\title{
Coupled ocean-atmosphere models with flux correction
}

\author{
R Sausen ${ }^{1}$, K Barthel ${ }^{2}$, and K Hasselmann ${ }^{3}$ \\ 1 Meteorologisches Institut, Universität Hamburg, Bundesstrasse 55, D-2000 Hamburg 13, Federal Republic of Germany \\ 2 Nansen Remote Sensing Centre, Edvard Griegsvei 3A, N-5037 Solheimsvik, Norway \\ 3 Max-Planck-Institut für Meteorologie, Bundesstrasse 55, D-2000 Hamburg 13, Federal Republic of Germany
}

\begin{abstract}
A method is proposed for removing the drift of coupled atmosphere-ocean models, which in the past has often hindered the application of coupled models in climate response and sensitivity experiments. The ocean-atmosphere flux fields exhibit inconsistencies when evaluated separately for the individual sub-systems in independent, uncoupled mode equilibrium climate computations. In order to balance these inconsistencies a constant ocean-atmosphere flux correction field is introduced in the boundary conditions coupling the two sub-systems together. The method ensures that the coupled model operates at the reference climate state for which the individual model subsystems were designed without affecting the dynamical response of the coupled system in climate variability experiments. The method is illustrated for a simple two component box model and an ocean general circulation model coupled to a two layer diagnostic atmospheric model.
\end{abstract}

\section{Introduction}

A characteristic feature of the climate system is its multi-time-scale structure, arising from the widely differing time scales of the basic climate sub-systems atmosphere, ocean, cryosphere and biosphere. This has an important influence both on the natural climate variability and on the time dependent response of the climate to anthropogenic or other external factors. To simulate these effects quantitatively, coupled models are needed.

Unfortunately, the coupling of different climate sub-systems poses a number of technical problems. An obvious problem arising from the

Offprint requests to: $\mathrm{R}$ Sausen different time scales is the synchronization or matching of the numerical integration of subsystems characterized by widely differing time steps. Here we consider another, more subtle problem, the problem of model drift. This has consistently hampered numerical experiments with coupled models (cf. Gates et al. 1985; Washington et al. 1980; Manabe et al. 1979). For illustration, we limit the discussion to the case of coupled oceanatmosphere models, but the analysis applies generally to any coupled system.

When two general circulation models of the atmosphere and ocean are coupled together in a single model, it is generally found that the coupled system gradually drifts into a new climate equilibrium state which is far removed from the observed climate. The coupled model climate equilibrium may be so unrealistic (for example, with respect to sea ice extent, or the oceanic equatorial current system) that climate response or sensitivity experiments relative to this state become meaningless. This occurs regularly even when the individual models have been carefully tested in detailed numerical experiments in the decoupled mode and have been shown to yield satisfactory simulations of the climate of the separate ocean or atmosphere sub-systems.

The drift of the coupled model is clearly a sign that something is amiss with the models. However, we suggest that it is not necessary to wait with climate response and sensitivity experiments with coupled models unit all causes of model drift have been properly identified and removed. Model drift is, in fact, an extremely sensitive indicator of model imperfections. The fact that the equilibrium climate into which a coupled model drifts is unacceptably far removed from the real climate does not necessarily imply that the model dynamics are too unrealistic for the model to be 
applied for climate response and sensitivity experiments. One should therefore devise methods for separating the drift problem from the basically independent problem of determining the change of the simulated climate induced by a change in boundary conditions and/or external forcing (climate response), and from the question of the effect of changes in the physical or numerical formulation of the model (model sensitivity).

The separation of the response and sensitivity analysis from the problem of simulating the mean climate has, of course, long been standard practice in climate experiments with atmospheric models. The change $\Delta \Phi$ in the climate state resulting from changes in the external forcing boundary conditions or model formulation is determined as the difference $\Delta \Phi=\Phi_{r}-\Phi_{c}$ between the climate $\Phi_{r}$ computed in a response experiment and the climate $\Phi_{c}$ of a control run simulating the mean climate. In this manner systematic deviations between the simulated and observed mean climate cancel, and the quality of the response computation depends only on the ability of the model to simulate the climate derivative $\partial \Phi / \partial e$ with respect to the relevant parameter $e$ describing the externally (or internally) induced climate change.

The same approach can be applied also to the case in which the control experiment is drifting in a coupled model (cf. Schlesinger et al. 1985). However, in this case the validity of the method is restricted to the finite time interval during which the model control climate has not drifted too far away from the initial (observed) climate state. This normally excludes precisely those time scales that one would like to study with a coupled model, namely the adjustment time scales of the slow system (in our case, the ocean), since these are identical to the time scales for the adjustment of the model to its incorrect equilibrium state.

However, the separation of the mean climate simulation from the climate response or sensitivity problem can be achieved for coupled models rather simply by an alternative technique, the flux correction method, which we describe in this paper. The errors that result in a drift of the coupled model are compensated in this method by constant correction terms in the flux expressions by which the separate sub-system models are coupled together. The correction terms have no influence on the dynamics of the system in climate response or sensitivity experiments, but ensure that the "working point" of the model lies close to the climate state for which the individual models were originally tuned.

A simple physical interpretation and the (rather straightforward) mathematical derivation of the flux correction technique are given in section 2. The method is illustrated for a simple example in section 3. A more realistic application to a global ocean circulation model coupled to a simplified diagnostic atmospheric model is presented in section 4. Section 5 describes an application of the technique, using the coupled model of section 4 , for a climate response experiment. The conclusions are summarized in the final section 6 .

\section{Drift removal by flux correction}

The basic principle of the flux correction method is to couple the atmosphere and the ocean in such a manner that in the unperturbed case each subsystem simulates its own mean climate in the same manner as in the uncoupled mode, but responds fully interactively to the other sub-system in climate response or sensitivity experiments. The method of coupling is indicated in electrical systems terminology in Fig. 1. The atmospheric and oceanic state vectors are denoted by $\Phi$ and $\Psi$, respectively. In the uncoupled mode (Fig. 1a), the boundary data $\Phi^{b}, \Psi^{b}$ required by each sub-system model is provided by obserations. In the fully coupled mode (Fig. 1b), the boundary data are computed from the other model, and the system adjusts to an equilibrium state which is determined only by the incoming solar radiation $S$ and by internal parameters of the model, such as surface albedo, atmospheric $\mathrm{CO}_{2}$ concentration, etc. In the flux correction method, the coupling is carried out only for variations $\left(\Phi^{\prime}, \Psi^{\prime}\right)$ of the climate state about its mean state $(\bar{\Phi}, \bar{\Psi})$. The mean state $(\bar{\Phi}, \bar{\Psi})$ in each system is established as in the

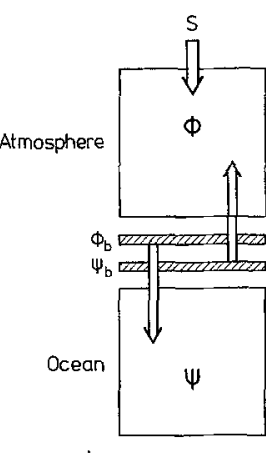

a

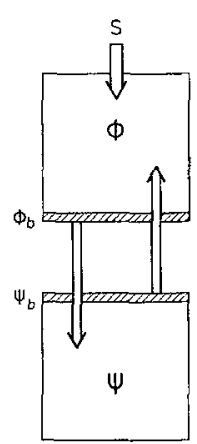

b

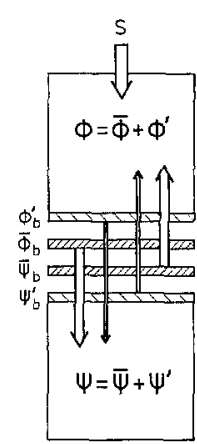

C
Fig. 1a-c. Boundary or coupling conditions of atmosphere and ocean models in different modes: a uncoupled; b fully coupled and $\mathrm{c}$ flux corrected 
uncoupled mode by the observed external boundary conditions. The basic principle of the flux correction method is that we distinguish between ' $A C$ ' and 'DC' components. In climate response and sensitivity experiments we are interested only in the 'AC' components. The flux correction method ensures that the 'working points' of the individual models are maintained at the values for which the models were designed, i.e., at the uncoupled model values, by maintaining the original mean 'bus voltages' $\bar{\Phi}, \bar{\Psi}$. ('AC' should be interpreted in this analogy not as 'high frequency components', but as any variation on any time scale about the reference state $\bar{\Phi}, \bar{\Psi}$. The 'coupling condensor' is infinitely large.)

If the mean climate state computed by the fully coupled model (Fig. 1b) lies close to the climate state predicted by the separate models (Fig. 1a), it is clear that within the framework of linear perturbation theory the flux corrected computation (Fig. 1c) should give results identical to the fully coupled computation for a small perturbation $\left(\Phi^{\prime}, \Psi^{\prime}\right)$. The difficulty with the fully coupled approach is that the differences between the equilibrium climates computed in the decoupled and coupled modes are generally too large to apply linearized theory. As pointed out above, this does not necessarily imply unacceptable inadequacies of the models, but is simply a consequence of the strong nonlinearity of the climate system. A $10 \mathrm{~K}$ change in the global mean temperature represents less than a $3 \%$ change of the global mean temperature of $288 \mathrm{~K}$. In terms of radiative fluxes, which are proportional to the fourth power of the temperature, this translates into a $12 \%$ flux error (keeping other factors constant). If all fluxes in the model can be computed to accuracies of this order, one would normally regard the model as sufficiently accurate for first order climate response studies. Nevertheless, a $10 \mathrm{~K}$ global temperature change implies a major distortion of the mean climate, and it would generally not be meaningful to use this state as a reference state for climate response or sensitivity experiments. A $10 \mathrm{~K}$ temperature increase could, for example, remove all sea ice and strongly diminish the high latitude response to an increase of $\mathrm{CO}_{2}$ concentration, cf. Manabe and Stouffer (1980). In the decoupled mode, flux errors in the $10 \%$ range do not seriously distort the mean climate of the subsystem, since the prescribed boundary values of the complementary sub-system prevent the modeled sub-system from drifting too far away from the observed state. The disparity between the very high model fidelity needed to simulate the mean climate with a coupled model and the less stringent requirements for response and sensitivity studies is overcome in the flux correction method by separating the mean climate and climate variation problems: the mean climate is simulated with the same accuracy as in the decoupled mode, while retaining the full dynamics of the coupled system in climate variation simulations.

To translate this concept into a specific correction procedure, consider a coupled atmosphere $(\Phi)$ ocean ( $\Psi$ ) model whose evolution is described by the equations

$$
\begin{aligned}
& \frac{\partial \Phi}{\partial t}=G_{A}(\Phi, t)+F\left(\Phi^{b}, \Psi^{b}, t\right)+E_{A}(\Phi, \Psi, t) \\
& \frac{\partial \Psi}{\partial t}=G_{O}(\Psi, t)-F\left(\Phi^{b}, \Psi^{b}, t\right)+E_{O}(\Phi, \Psi, t)
\end{aligned}
$$

where $G_{A}$ and $G_{O}$ are source functions representing all physical processes occurring within the atmospheric and oceanic sub-system, and $F$ is the flux between the sub-systems (positive from ocean to atmosphere). We assume that the model evolution differs from the evolution of the true system $\left(\Phi_{\text {true }}, \Psi_{\text {true }}\right)$ by (unknown) model errors $E_{A}, E_{O}$ :

$$
\begin{aligned}
& \frac{\partial \Phi}{\partial t}=\frac{\partial \Phi_{\text {true }}}{\partial t}+E_{A}(\Phi, \Psi, t) \\
& \frac{\partial \Psi}{\partial t}=\frac{\partial \Psi_{\text {true }}}{\partial t}+E_{O}(\Phi, \Psi, t)
\end{aligned}
$$

A long term strategy of model development must be clearly directed towards identifying and correcting the model errors $E_{A}$ and $E_{O}$. For complex nonlinear systems, this is generally very time consuming. We consider here the situation in which the errors are already small and we simply wish to remove the drift they cause without otherwise influencing the dynamics of the model.

A possible method to prevent the model equilibrium state from departing too strongly from the observed equilibrium is to introduce a Newtonian correction term (as used, e.g., by Sarmiento and Bryan, 1982, in their "robust diagnostic" ocean model). The model equations then take the form

$$
\begin{aligned}
\frac{\partial \Phi}{\partial t}= & G_{A}(\Phi, t)+F\left(\Phi^{b}, \Psi^{b}, t\right) \\
& +E_{A}-M_{A}\left(\Phi-\Phi_{m}\right)
\end{aligned}
$$




$$
\begin{aligned}
\frac{\partial \Psi}{\partial t}= & G_{O}(\Psi, t)-F\left(\Phi^{b}, \Psi^{b}, t\right) \\
& +E_{O}-M_{O}\left(\Psi-\Psi_{m}\right)
\end{aligned}
$$

where $\Phi_{m}$ and $\Psi_{m}$ are the observed (measured) atmospheric and oceanic variables, respectively, and $M_{A}$ and $M_{O}$ are (normally diagonal) matrices of the Newtonian correction coefficients. In general, relatively large Newtonian coefficients are needed in order to reduce the drift of the coupled mean deviation to the same level as the errors of the uncoupled models, so that the system response is significantly dampened. Thus the dynamics of the system is changed, and the method cannot be used for our applications.

In the flux correction method, the errors $E_{A}, E_{O}$ in Eqs. (2.1), (2.2) are balanced in the equilibrium state by constant additive flux terms $\Delta F_{A}$ and $\Delta F_{O}$ :

$$
\begin{aligned}
& \frac{\partial \Phi}{\partial t}=G_{A}(\Phi, t)+F\left(\Phi^{b}, \Psi^{b}, t\right)+E_{A}+\Delta F_{A} \\
& \frac{\partial \Psi}{\partial t}=G_{O}(\Psi, t)-F\left(\Phi^{b}, \Psi^{b}, t\right)+E_{O}-\Delta F_{O}
\end{aligned}
$$

We choose the flux corrections such that the equilibrium climate $\left(\Phi_{c}, \Psi_{c}\right)$ of the coupled systems is identical to the equilibrium climate $\left(\Phi_{u}, \Psi_{u}\right)$ attained by each of the sub-systems separately when run in the uncoupled mode. (It is the basic premise of our method that this lies close to the true climate.) Substituting the desired equilibrium climate $\left(\Phi_{u}, \Psi_{u}\right)$ into Eqs. (2.7) and (2.8) and subtracting from these the equations for the equilibrium climates of the sub-systems when computed in the uncoupled mode,

$$
\begin{aligned}
& \frac{\partial \Phi_{u}}{\partial t}=G_{A}\left(\Phi_{u}, t\right)+F\left(\Phi_{u}^{b}, \Psi_{m}^{b}, t\right)+E_{A} \\
& \frac{\partial \Psi_{u}}{\partial t}=G_{O}\left(\Psi_{u}, t\right)-F\left(\Phi_{m}^{b}, \Psi_{u}^{b}, t\right)+E_{O}
\end{aligned}
$$

we obtain

$$
\begin{aligned}
& \Delta F_{A}=F\left(\Phi_{u}^{b}, \Psi_{m}^{b}, t\right)-F\left(\Phi_{u}^{b}, \Psi_{u}^{b}, t\right) \\
& \Delta F_{O}=F\left(\Phi_{m}^{b}, \Psi_{u}^{b}, t\right)-F\left(\Phi_{u}^{b}, \Psi_{u}^{b}, t\right)
\end{aligned}
$$

It is seen that by supplying to each sub-system a flux correction representing the difference between the flux computed in the uncoupled experi- ment, using observed data for the boundary value of the complementary system, and the flux computed using the boundary values determined in each of the uncoupled experiments, each subsystem receives the flux required to establish the same equilibrium as was found in the uncoupled mode. The constant additive fluxes cancel when considering the deviations of the climate state relative to some reference state, and thus have no effect in climate response or sensitivity experiments.

In the above analysis we have retained the time dependence throughout, since we define the climate equilibrium solution generally as climate states which are ensemble averaged to exclude the statistical variability, but include the annual cycle. According to Eqs. (2.11), (2.12), the computation of the flux correction terms requires only diagnostic computations of the fluxes for boundary values taken from the uncoupled mode solutions or from observations. For simple systems with a few degrees of freedom, the flux correction term can also be determined from the rate of drift of the coupled system. However, for more complex systems it is generally not straightforward to relate the rate of drift of the full climate state vectors to the individual flux corrections which need to be applied to the separate sub-systems to balance the drift.

\section{An example}

To illustrate the flux corretion method, we consider a simple nonlinear ocean-atmosphere model with two degrees of freedom. The atmosphere and the ocean are described by their temperatures $T_{A}$ and $T_{O}$, which are governed by the energy balance equations

$$
\begin{aligned}
& C_{A} \frac{d T_{A}}{d t}=R_{A}-\lambda_{A} T_{A}+k\left(T_{O}-T_{A}\right) \\
& C_{O} \frac{d T_{O}}{d t}=R_{O}-\lambda_{O} T_{O}-k\left(T_{O}-T_{A}\right)
\end{aligned}
$$

Here $C_{A}$ and $C_{O}$ denote the atmospheric and oceanic heat capacities, $R_{A}$ and $R_{O}$ the solar energy input to each system, $\lambda_{A} T_{A}$ and $\lambda_{O} T_{O}$ represent the radiative losses (linearized about reference temperatures), and $k\left(T_{O}-T_{A}\right)$ the flux of energy from the ocean to the atmosphere. $R_{A}$ is taken as constant, but $R_{O}$ is represented as the nonlinear function 
$R_{O}\left(T_{O}\right)= \begin{cases}R_{O}^{(1)} & \text { for } T_{O} \leq T_{O}^{(1)} \\ R_{O}^{(1)}+\frac{T_{O}-T_{O}^{(1)}}{T_{O}^{(2)}-T_{O}^{(1)}}\left(R_{O}^{(2)}-R_{O}^{(1)}\right) & \text { for } T_{O}^{(1)}<T_{O}<T_{O}^{(2)} \\ R_{O}^{(2)} & \text { for } T_{O}^{(2)} \leq T_{O}\end{cases}$

where $R_{O}^{(2)}>R_{O}^{(1)}$. The form (3.3) corresponds to the traditional representation of the nonlinear sea-ice albedo feedback in energy balance models. For $T_{O} \leqq T_{O}^{(1)}$, the sea surface is completely ice covered, while for $T_{o} \geqq T_{o}^{(2)}$ the sea surface is ice free.

We take as the observed atmospheric and oceanic temperatures $T_{A}^{(m)}=286 \mathrm{~K}$ and $T_{O}^{(m)}=$ $288 K$. A "perfect" model, which reproduces these values, is given by the set of parameters $P M$ in Table 1. We assume that the perfect model is not known and that we have constructed an approximate model, whose parameters $A M$ are also listed in Table 1. The model $A M$ is assumed to have been tested for each sub-system in the uncoupled mode and we now wish to apply the model in the coupled mode for a response experiment.

In the uncoupled mode, the atmospheric model is driven by the observed oceanic temperature $T_{O}^{(m)}$ while the ocean model is forced by the observed atmospheric temperature $T_{A}^{(m)}$,

$$
C_{A} \frac{d T_{A}}{d t}=R_{A}-\lambda_{A} T_{A}+k\left(T_{O}^{(m)}-T_{A}\right)
$$

Table 1. Numerical values of the coefficients of the "perfect" model PM and the approximate model AM

\begin{tabular}{|c|c|c|}
\hline & Atmosphere & Ocean \\
\hline Heat capacity & $C_{A}=10^{7} \mathrm{~J} /\left(\mathrm{m}^{2} \mathrm{~K}\right)$ & $C_{O}=10^{8} \mathrm{~J} /\left(\mathrm{m}^{2} \mathrm{~K}\right)$ \\
\hline Solar input & $R_{A}=130 \mathrm{~W} / \mathrm{m}^{2}$ & $\begin{array}{l}R_{O}^{(1)}=120 \mathrm{~W} / \mathrm{m}^{2} \\
R_{O}^{(2)}=125 \mathrm{~W} / \mathrm{m}^{2}\end{array}$ \\
\hline $\begin{array}{l}\text { Reference } \\
\text { temperatures }\end{array}$ & & $\begin{array}{l}T_{O}^{(1)}=290 K \\
T_{O}^{(2)}=295 K\end{array}$ \\
\hline $\begin{array}{l}\text { Coupling } \\
\text { constant }\end{array}$ & $k=10 \mathrm{~W} /\left(\mathrm{m}^{2} \mathrm{~K}\right)$ & $k=10 \mathrm{~W} /\left(\mathrm{m}^{2} \mathrm{~K}\right)$ \\
\hline $\begin{array}{l}\text { Newtonian } \\
\text { coefficients }\end{array}$ & $m_{A}=10 \mathrm{~W} /\left(\mathrm{m}^{2} \mathrm{~K}\right)$ & $m_{O}=15 \mathrm{~W} /\left(\mathrm{m}^{2} \mathrm{~K}\right)$ \\
\hline $\begin{array}{r}P M \text { emissivity } \\
\text { control } \\
\text { reduced }\end{array}$ & $\begin{array}{l}\lambda_{A}=0.5245 \mathrm{~W} /\left(\mathrm{m}^{2} \mathrm{~K}\right) \\
\lambda_{A}=0.5144 \mathrm{~W} /\left(\mathrm{m}^{2} \mathrm{~K}\right)\end{array}$ & $\begin{array}{l}\lambda_{o}=0.3472 \mathrm{~W} /\left(\mathrm{m}^{2} \mathrm{~K}\right) \\
\lambda_{0}=0.3472 \mathrm{~W} /\left(\mathrm{m}^{2} \mathrm{~K}\right)\end{array}$ \\
\hline $\begin{array}{r}A M \text { emissivity } \\
\text { control } \\
\text { reduced }\end{array}$ & $\begin{array}{l}\lambda_{A}=0.5200 \mathrm{~W} /\left(\mathrm{m}^{2} \mathrm{~K}\right) \\
\lambda_{A}=0.5100 \mathrm{~W} /\left(\mathrm{m}^{2} \mathrm{~K}\right)\end{array}$ & $\begin{array}{l}\lambda_{o}=0.3400 \mathrm{~W} /\left(\mathrm{m}^{2} \mathrm{~K}\right) \\
\lambda_{o}=0.3400 \mathrm{~W} /\left(\mathrm{m}^{2} \mathrm{~K}\right)\end{array}$ \\
\hline
\end{tabular}

$$
C_{O} \frac{d T_{o}}{d t}=R_{O}-\lambda_{o} T_{O}-k\left(T_{O}-T_{A}^{(m)}\right)
$$

The atmospheric model has a unique steady state solution

$$
T_{A}^{(u)}=\frac{R_{A}+k T_{O}^{(m)}}{\lambda_{A}+k}
$$

The ocean model can have either one stable steady state solution or two stable solutions and one unstable solution, depending on the values of the parameters. The stable solutions lie in the first or third regions of Eq. (3.3) on either side of the unstable middle region, and are given by

$$
T_{O}^{(u)}=\frac{R_{O}^{(i)}+k T_{A}^{(m)}}{\lambda_{O}+k}
$$

The index $i$ may take on both values 1 and 2 or only one of the two, depending on whether the values of $T_{O}(u)$ determined by Eq. (3.7) are consistent with the inequalities defining the temperature range for a given $R^{(i)}$ in Eq. (3.3). For $P M$, $\left(T_{A}^{(m)}, T_{O}^{(m)}\right)$ is the only solution. The model $A M$ also yields only one stable solution: $T_{A}^{(u)}=286.12 \mathrm{~K}$, $T_{O}^{(u)}=288.20 \mathrm{~K}$, differing slightly from the solution $P M$, which reproduces the observations.

The equilibrium heat flux into the atmosphere for the uncoupled atmospheric model $A M$ is determined as

$$
\begin{aligned}
F_{A} & =F\left(\mathrm{~T}_{A}^{(u)}, T_{O}^{(m)}\right)=k\left(T_{O}^{(m)}-T_{A}^{(u)}\right) \\
& =18.78 \mathrm{~W} / \mathrm{m}^{2}
\end{aligned}
$$

while the corresponding flux for the uncoupled ocean model $A M$ is

$$
\begin{aligned}
F_{O} & =F\left(T_{A}^{(m)}, T_{O}^{(u)}\right)=k\left(T_{O}^{(u)}-T_{A}^{(m)}\right) \\
& =22.01 \mathrm{~W} / \mathrm{m}^{2}
\end{aligned}
$$

An atmospheric "climate response" experiment, in which the parameter $\lambda_{A}$ (representing for example a change in the greenhouse effect) is reduced by $2 \%$ (see Table 1) while the sea surface temperature is kept fixed, results in a small increase of the atmospheric temperature $\left(\Delta T_{A}^{(m)}=\right.$ $0.27 K$ for $P M$ and $A M$ ). As the atmosphere is 
strongly coupled to the ocean, only a weak response is possible. (For a summary of the numerical results see Table 2.)

The coupled model also has either one or two stable equilibrium solutions:

$$
\begin{aligned}
T_{O}^{(c)} & =\frac{\left(k+\lambda_{A}\right) R_{O}^{(i)}+k R_{A}}{\lambda_{A} \lambda_{O}+\left(\lambda_{A}+\lambda_{O}\right) k}, i=1,2 \\
T_{A}^{(c)} & =\frac{R_{A}+k T_{O}^{(c)}}{\lambda_{A}+k}
\end{aligned}
$$

For $P M$ again only one stable solution exists, $T_{A}^{(c)}=T_{A}^{(m)}, T_{O}^{(c)}=T_{O}^{(m)}$. For $A M$ the coupled model drifts into a new equilibrium climate state, $T_{A}^{(c)}=$ $295.57 K, T_{o}^{(c)}=297.94 K$ (see Fig. 2, solid curves). The flux from the ocean into the atmosphere for this equilibrium is given by

$$
F_{C}=F\left(T_{A}^{(c)}, T_{O}^{(c)}\right)=k\left(\mathrm{~T}_{O}^{(c)}-T_{A}^{(c)}\right)=23.7 \mathrm{~W} / \mathrm{m}^{2}
$$

\begin{tabular}{|c|c|c|c|c|}
\hline & & Control & $\begin{array}{l}\text { Reduced } \\
\text { emissivity }\end{array}$ & Difference \\
\hline Observed & $\begin{array}{l}T_{A}^{(m)} \\
T_{O}^{(m)}\end{array}$ & $\begin{array}{l}286.00 \\
288.00\end{array}$ & - & - \\
\hline $\begin{array}{l}\text { Uncoupled } \\
A M\end{array}$ & $\begin{array}{l}T_{A}^{(u)} \\
T_{O}^{(u)} \\
T_{A}^{(u)}-T_{A}^{(m)} \\
T_{O}^{(u)}-T_{O}^{(m)}\end{array}$ & $\begin{array}{r}286.12 \\
288.20 \\
0.12 \\
0.20\end{array}$ & $\begin{array}{r}286.39 \\
288.20 \\
0.39 \\
0.20\end{array}$ & $\begin{array}{l}0.27 \\
0.00 \\
- \\
-\end{array}$ \\
\hline $\begin{array}{l}\text { Uncoupled } \\
P M\end{array}$ & $\begin{array}{l}T_{A}^{(u)} \\
T_{O}^{(u)} \\
T_{A}^{(u)}-T_{A}^{(m)} \\
T_{O}^{(u)}-T_{O}^{(m)}\end{array}$ & $\begin{array}{r}286.00 \\
288.00 \\
0.00 \\
0.00\end{array}$ & $\begin{array}{r}286.27 \\
288.00 \\
0.27 \\
0.00\end{array}$ & $\begin{array}{l}0.27 \\
0.00 \\
- \\
-\end{array}$ \\
\hline $\begin{array}{l}\text { Coupled } \\
\text { without } \\
\text { flux } \\
\text { correction }\end{array}$ & $\begin{array}{l}T_{A}^{(c)} \\
T_{O}^{(c)} \\
T_{A}^{(c)}-T_{A}^{(m)} \\
T_{O}^{(c)}-T_{O}^{(m)}\end{array}$ & $\begin{array}{r}295.57 \\
297.94 \\
9.57 \\
9.94\end{array}$ & $\begin{array}{r}299.10 \\
301.35 \\
13.10 \\
13.35\end{array}$ & $\begin{array}{l}3.53 \\
3.41 \\
- \\
-\end{array}$ \\
\hline $\begin{array}{l}\text { Coupled } \\
\text { with } \\
\text { Newtonian } \\
\text { forcing }\end{array}$ & $\begin{array}{l}T_{A}^{(n)} \\
T_{O}^{(n)} \\
T_{A}^{(n)}-T_{A}^{(m)} \\
T_{O}^{(n)}-T_{O}^{(m)}\end{array}$ & $\begin{array}{r}286.13 \\
288.13 \\
0.13 \\
0.13\end{array}$ & $\begin{array}{r}286.30 \\
288.20 \\
0.30 \\
0.20\end{array}$ & $\begin{array}{l}0.17 \\
0.07 \\
- \\
-\end{array}$ \\
\hline $\begin{array}{l}\text { Coupled } \\
\text { with flux } \\
\text { correction }\end{array}$ & $\begin{array}{l}T_{A}^{(c)} \\
T_{O}^{(c)} \\
T_{A}^{(c)}-T_{A}^{(m)} \\
T_{O}^{(c)}-T_{O}^{(m)}\end{array}$ & $\begin{array}{r}286.12 \\
288.20 \\
0.12 \\
0.20\end{array}$ & $\begin{array}{r}295.30 \\
297.56 \\
9.30 \\
9.56\end{array}$ & $\begin{array}{l}9.18 \\
9.36 \\
- \\
-\end{array}$ \\
\hline Coupled & $\begin{array}{l}T_{A}^{(c)} \\
T_{O}^{c)}\end{array}$ & $\begin{array}{l}286.00 \\
288.00\end{array}$ & $\begin{array}{l}295.08 \\
297.28\end{array}$ & $\begin{array}{l}9.08 \\
9.28\end{array}$ \\
\hline$P M$ & $\begin{array}{l}T_{A}^{(c)}-T_{A}^{(m)} \\
T_{O}^{(c)}-T_{O}^{(m)}\end{array}$ & $\begin{array}{l}0.00 \\
0.00\end{array}$ & $\begin{array}{l}9.08 \\
9.28\end{array}$ & - \\
\hline
\end{tabular}

Table 2. Results of the simple coupled ocean atmosphere model. Temperatures in $K$
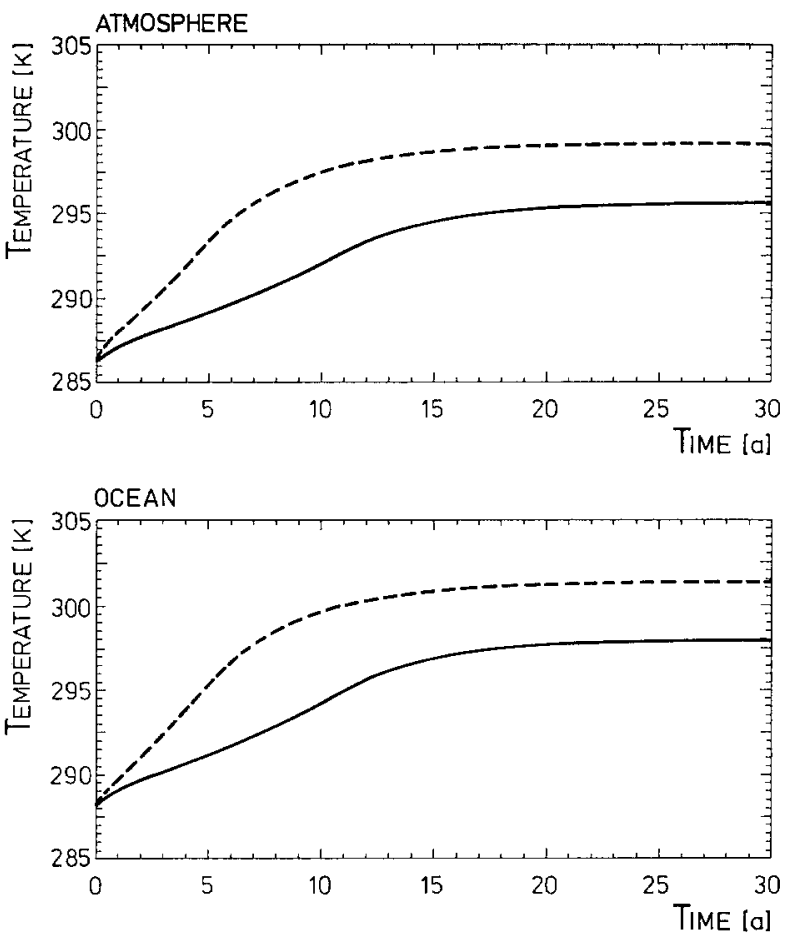

Fig. 2. A coupled nonlinear ocean-atmosphere model with two degrees of freedom. Time evolution of the control run (solid line) and the reduced emissitivity run (dashed line) without flux correction

A "climate response" experiment with the modified value $\lambda_{A}$ (dashed lines in Fig. 2) results in a change of the coupled model of $\Delta T_{A}^{(c)}=3.53 \mathrm{~K}$ and $\Delta T_{O}^{(c)}=3.41 \mathrm{~K}$. This is significantly smaller than both the climate drift and the true coupled response of $P M\left(\Delta T_{A}=9.08 \mathrm{~K}, \Delta T_{O}=9.28 \mathrm{~K}\right)$.

If Newtonian feedback terms are introduced, as in Eqs. (2.5), (2.6), the model takes the form

$$
\begin{aligned}
C_{A} \frac{d T_{A}}{d t}= & R_{A}-\lambda_{A} T_{A}+k\left(T_{O}-T_{A}\right) \\
& -m_{A}\left(T_{A}-T_{A}^{(m)}\right) \\
C_{O} \frac{d T_{O}}{d t}= & R_{O}-\lambda_{O} T_{O}-k\left(T_{O}-T_{A}\right) \\
& -m_{O}\left(T_{O}-T_{O}^{(m)}\right)
\end{aligned}
$$

Setting $m_{A}=10 W /\left(\mathrm{m}^{2} K\right)$ and $m_{O}=15 W /\left(\mathrm{m}^{2} K\right)$, for example, the drift of the coupled model $A M$ is reduced to $0.13 \mathrm{~K}$ for both the atmospheric and the oceanic temperature. However, the response to the changed $\lambda_{A}$ is now also drastically dampened: $\Delta T_{A}^{(n)}=0.17 \mathrm{~K}, \Delta T_{O}^{(n)}=0.07 \mathrm{~K}$.

If we resolve the drift problem by the flux correction method, the corresponding flux corrections according to Eqs. (2.11), (2.12) are given by 


$$
\begin{aligned}
\Delta F_{A} & =F\left(T_{A}^{(u)}, T_{O}^{(m)}\right)-F\left(T_{A}^{(u)}, T_{O}^{(u)}\right) \\
& =-k\left(T_{O}^{(u)}-T_{O}^{(m)}\right)=-2.01 \mathrm{~W} / \mathrm{m}^{2} \\
\Delta F_{O} & =F\left(T_{A}^{(m)}, T_{O}^{(u)}\right)-F\left(T_{A}^{(u)}, T_{O}^{(u)}\right) \\
& =+k\left(T_{A}^{(u)}-T_{A}^{(m)}\right)=1.22 W / \mathrm{m}^{2}
\end{aligned}
$$

and the model equations take the form

$$
\begin{aligned}
C_{A} \frac{d T_{A}}{d t}= & R_{A}-\lambda_{A} T_{A}+k\left(T_{O}-T_{A}\right) \\
& -k\left(T_{O}^{(u)}-T_{O}^{(m)}\right) \\
C_{O} \frac{d T_{O}}{d t}= & R_{O}-\lambda_{O} T_{O}-k\left(T_{O}-T_{A}\right) \\
& -k\left(T_{A}^{(u)}-T_{A}^{(m)}\right)
\end{aligned}
$$

The equilibrium model climate is now preserved as in the uncoupled case (see Fig. 3, solid lines). The climate response to a variation of $\lambda_{A}$ is determined as $\Delta T_{A}^{(c)}=9.18 \mathrm{~K}$ and $\Delta T_{O}^{(c)}=9.36 \mathrm{~K}$, which agrees with the true response within $1 \%$ (cf. Table 2).

\section{Coupling of an oceanic general circulation model to a diagnostic atmospheric model}

The global ocean circulation model used for this coupling experiment is based on the model de-
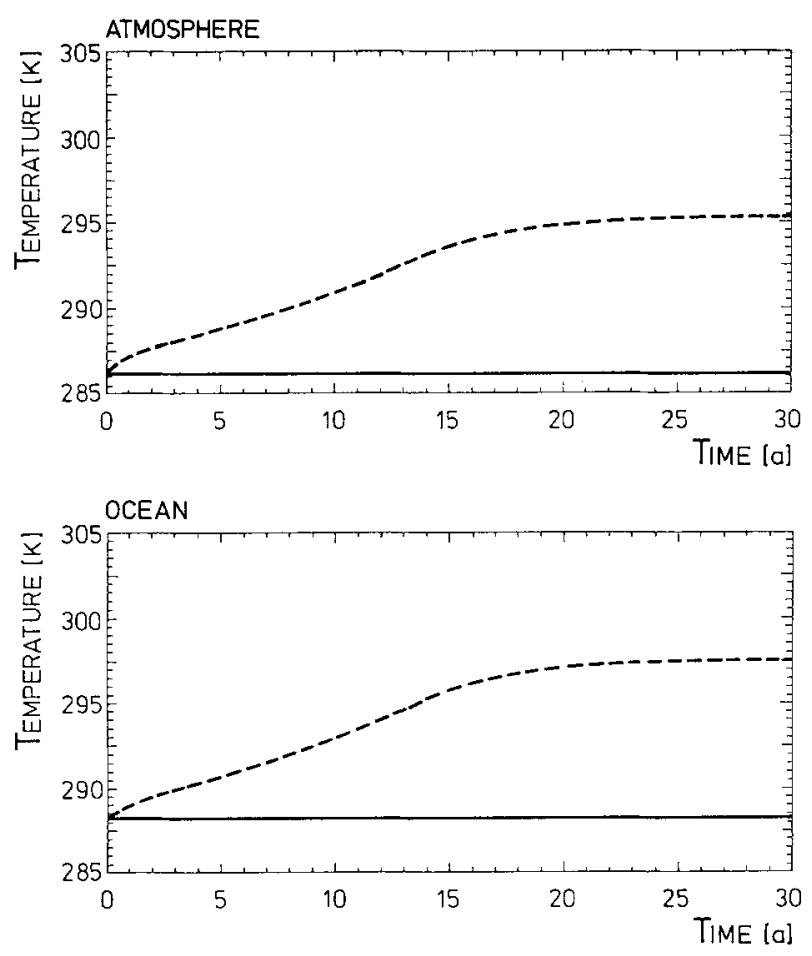

Fig. 3. Same as Fig. 2, but with flux correction scribed in Maier-Reimer et al. (1983) and MaierReimer (1985) (see also Maier-Reimer and Hasselmann, 1987). Salinity and temperature are transported in the model by advection only, except for local convection in high latitude regions to maintain static stability and numerical diffusion. The model includes a realistic bottom topography and is run in the present experiment using a $3.54^{\circ} \times 3.54^{\circ}$ horizontal grid mesh with 5 vertical levels (at 75, 150, 300, 1000 and $3000 \mathrm{~m}$ depth for the horizontal velocity, temperature and salinity, and at 112, 225, 650,2000 and $6000 \mathrm{~m}$ for the vertical velocity). In the uncoupled model the circulation is driven by Hellerman's (1967) wind stress using the observed surface values of the salinity and temperature from Levitus and Oort (1977) as surface boundary conditions. The model was run without a seasonal cycle. Sea ice was not included, but the density was kept constant if the temperature dropped below the freezing point.

The atmospheric model is a two layer radiative convective model with horizontal coupling through temperature advection by the observed wind and a (weak) diffusive transport. The evolution equation for the temperature field $T$ is given by

$$
\frac{\partial T}{\partial t}=-\nabla \cdot \mathrm{V} T-r \frac{\partial(\omega \theta)}{\partial p}+D \nabla^{2} T+\frac{Q}{c_{p}}
$$

where $V$ represents the horizontal wind, $\omega$ the vertical component of the wind, $p$ the pressure, $D$ a diffusion constant, $Q$ the diabatic heating, $c_{p}$ the heat specific at constant pressure, and $\theta$ the potential temperature. This is given by

$$
r \theta=T
$$

with

$$
r=\left(\frac{p}{p_{o o}}\right)^{R / c_{p}}
$$

where $R$ is the gas constant and $p_{o o}$ a reference pressure. The observed wind $V$ is the zonal and annual mean calculated from Oort's (1983) data. The vertical wind $\omega$ is determined from the prescribed horizontal wind by the continuity equation

$$
\nabla \cdot V+\frac{\partial \omega}{\partial p}=0
$$

The atmosphere is driven by the annual solar radiation (Coakley 1979) and by the annual mean 
of sea surface temperature (SST). In the uncoupled case, this was taken from Levitus and Oort (1977), while in the coupled case it is computed by the oceanic model. The surface temperature over land is calculated as the radiative convective equilibrium temperature. A snow-ice albedo parameterization with a step function temperature dependence at $0^{\circ} \mathrm{C}$ was used. The model was integrated on a $2.5^{\circ} \times 5^{\circ}$ latitude-longitude $\mathrm{C}$-grid with the two (temperature) levels at $400 \mathrm{hPa}$ and $800 \mathrm{hPa}$. For more details see Sausen (1987).

In the coupled experiments, the total heat flux coupling the two systems was computed from the sea surface temperature $T_{s}$, taken as the temperature of the uppermost ocean layer $(75 \mathrm{~m}$ depth), and the temperature $T_{3}$ of the lowest atmospheric level according to

$$
F=-\varepsilon_{s} S-\alpha_{3} \sigma_{B} T_{3}^{4}+\alpha_{s} \sigma_{B} T_{s}^{4}+H_{S}
$$

$F$ consists of the sum of the incoming solar radiation $\varepsilon_{S} S$ (into the ocean), the infrared radiation $\alpha_{3} \sigma_{B} T_{3}^{4}$ and $\alpha_{s} \sigma_{B} T_{S}^{4}$ absorbed and emitted by the ocean, respectively, and the sensible plus latent heat flux $H_{s}$ emitted by the ocean, which we parameterized by the bulk formula

$$
H_{s}= \begin{cases}h_{s}\left(\Theta_{s}-\Theta_{3}\right), & \text { if } \Theta_{s}>\Theta_{3} \\ 0 & , \text { if } \Theta_{s} \leq \Theta_{s}\end{cases}
$$

with a constant $h_{s}$.

The oceanic model uses an implicit time integration scheme with a time step of one month. With respect to this time step the atmospheric model can be run in a diagnostic mode. However, the equilibrium atmospheric state was actually computed by integrating the atmospheric model, using the prognostic equation (4.1) with a 1 hour time step, for 240 time steps (ten days). (This technique was affordable as the atmospheric model requires little computer time.)

The equilibrium temperature fields of the atmospheric model in the uncoupled mode are shown in Fig. 4. As only a small diffusion coefficient was used $\left(D=1.75 \cdot 10^{-6} \mathrm{~m}^{2} / \mathrm{s}\right)$, the temperature fields exhibit a structure which is rather too zonal. Figure 5 shows the corresponding equilibrium temperature fields of the oceanic model in the uncoupled mode. This oceanic state was achieved after 20000 years integration. As the boundary conditions for salinity and wind were not changed in the coupled case, we shall consider only the temperature fields in the following (although the salinity and velocity fields were, of course, also modified in the coupled case).
The total heat flux from the ocean into the atmosphere computed from the atmospheric model in the uncoupled mode is shown in Fig. 6. One obtains the expected global structure, with a flux into the ocean in the tropics and out of the ocean at high latitudes. The upwelling areas in the eastern Pacific and eastern Atlantic stand out clearly as maxima of positive flux into the ocean. The Gulfstream region and the Norwegian Sea appear as areas with a large flux into the atmosphere. The high values of the flux from the ocean into the atmosphere in the Arctic Sea is strongly exaggerated in the present oceanic model due to the lack of sea ice.

The sea-air heat flux of the uncoupled ocean, shown in Fig. 7, differs significantly from the flux computed for the uncoupled atmosphere, Fig. 6. In the North Atlantic and the Norwegian Sea, for example, the atmospheric model yields a heat flux into, rather than out of the ocean. The differences represent an incompatibility of the models which must be corrected for if both models are to be coupled together. (It could well be argued in the present case that the atmospheric model is considerably less realistic than the oceanic model, and that the "state of the art" of this model does not really justify its use with an ocean model in a coupled mode. Nevertheless, to illustrate the method we assume that we are satisfied with the performance of the atmospheric model in the uncoupled mode.)

One of the terms occurring in the flux correction expressions is the sea-air flux computed from the boundary values of the atmosphere and ocean derived from the equilibrium states of the separate uncoupled model experiments [cf. Eqs. (2.11) and (2.12)]. This is shown in Fig. 8. The field exhibits a structure similar to that of Fig. 6. The flux correction for the atmosphere is the difference of the flux fields of Figs. 6 and 8, and is plotted in Fig. 9. The flux correction is generally small over tropical and midlatitude oceans. However, in the northern Atlantic, the Norwegian Sea, the Arctic Sea, the Weddell Sea and the Ross Sea, it is of the same order as the flux itself. This may again be attributed in part to the lack of sea ice. The flux correction for the ocean (Fig. 10) shows rather large values in many regions. This is presumably mainly governed by insufficiencies of the atmospheric model.

Starting from the equilibrium solutions of the uncoupled models, the coupled model was integrated for one hundred years both without and with flux correction. The temporal evolution of the global mean temperature of the atmosphere 

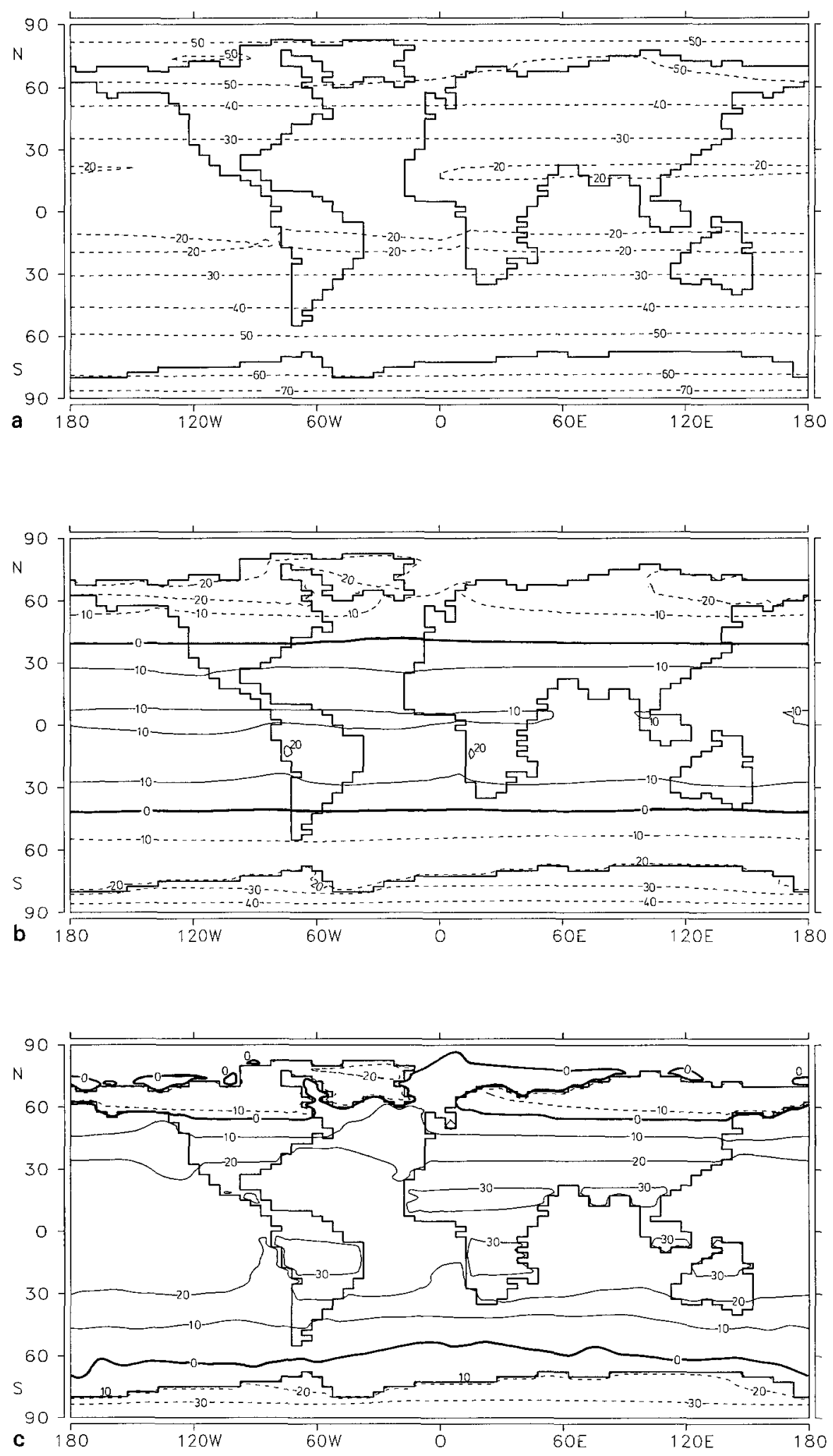

Fig. 4a-c. Equilibrium temperature fields in ${ }^{\circ} \mathrm{C}$ of the two level atmospheric energy balance model; a $400 \mathrm{hPa}$; b $800 \mathrm{hPa}$; c surface. Isoline intervals are $10^{\circ} \mathrm{C}$. Negative isolines are dashed 

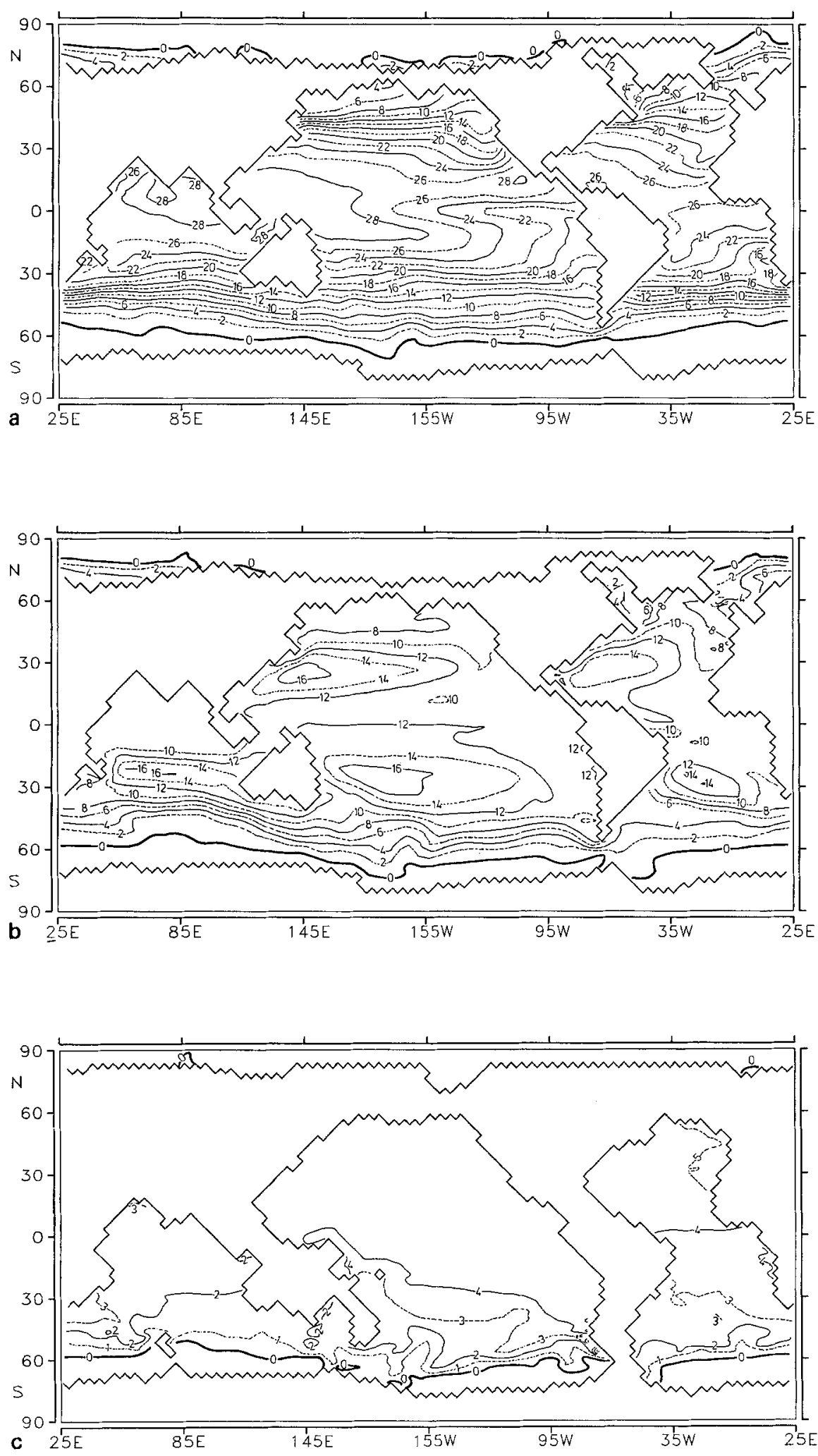

Fig. 5a-c. Equilibrium temperature fields of the global ocean general circulation model. a 75 $\mathrm{m} ;$ b $300 \mathrm{~m} ; \mathbf{c} 3000 \mathrm{~m}$. Isoline intervals are $2^{\circ} \mathrm{C}$ for panels a and $\mathbf{b}, 1^{\circ} \mathrm{C}$ for panel $\mathbf{c}$ 


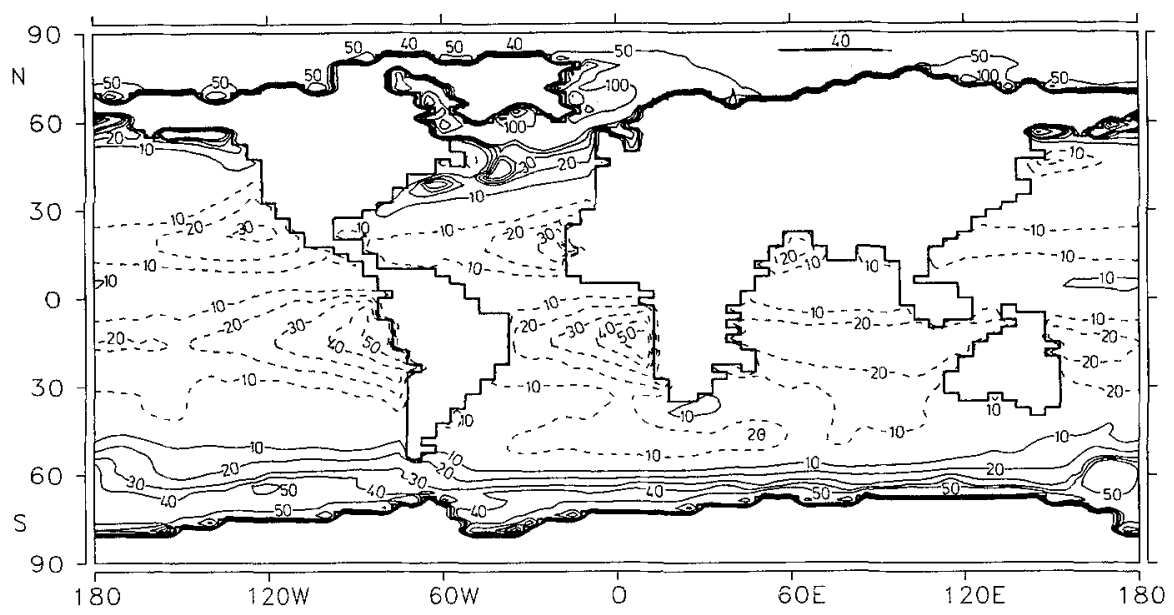

Fig. 6. Sea-air heat flux of the atmospheric model in the uncoupled mode. Isoline intervals are $10 \mathrm{Wm}^{-2}$ below $50 \mathrm{Wm}^{-2}$, $50 \mathrm{Wm}^{-2}$ above $50 \mathrm{Wm}^{-2}$. Negative isolines are dashed for both cases is plotted in Fig. 11. Without flux correction, the coupled-run climate drifts away rapidly from the uncoupled-run climate. The original surface temperature of $16.1^{\circ} \mathrm{C}$ decreases by $1.9 \mathrm{~K}$ in the first 10 years and by $4.1 \mathrm{~K}$ within 100 years. The drift for levels 1 and 2 is somewhat smaller, $-3.3 \mathrm{~K}$ and $-3.7 \mathrm{~K}$, respectively, within 100 years. With flux correction, the temperatures remain close to the initial values. The deviation is less than $0.01 K$ for all levels.

The flux correction method removes not only the drift of the mean temperature, but also reduces the temperature drift at individual gridpoints. This can be inferred from Fig. 12, where the evolution of the rms deviation of the temperature from the initial values is plotted. Without flux correction, the rms deviation increases rapidly and reaches values between 3 and $6 K$ within 100 years. With flux correction, the rms deviation remains two orders of magnitude smaller. As will be seen below, the residual drift is mostly due to a small drift of the uncoupled oceanic model, which had not completely achieved equilibrium when the coupled model run was started.

Figure 13 shows the horizontal distribution of the temperature change at level 2 over 100 years. Without flux correction the drift is largest over arctic regions and over the tropical Pacific. With flux correction a residual drift can be observed at only very few points. The drift is larger than $1.0 \mathrm{~K}$ and $0.5 \mathrm{~K}$ at only 6 and 29 gridpoints, respectively, out of a total of 5042 gridpoints. The results (not shown) for level 1 and the surface are similar.

The global mean temperatures of the ocean (Fig. 14) also drift away in the coupled run without flux correction. In contrast to the atmosphere, where the drift constant is approximately the same for all levels (it is effectively determined by the SST drift rate), the drift rate in the ocean is seen to be strongly dependent on depth. As expected, the deeper layers drift more slowly and

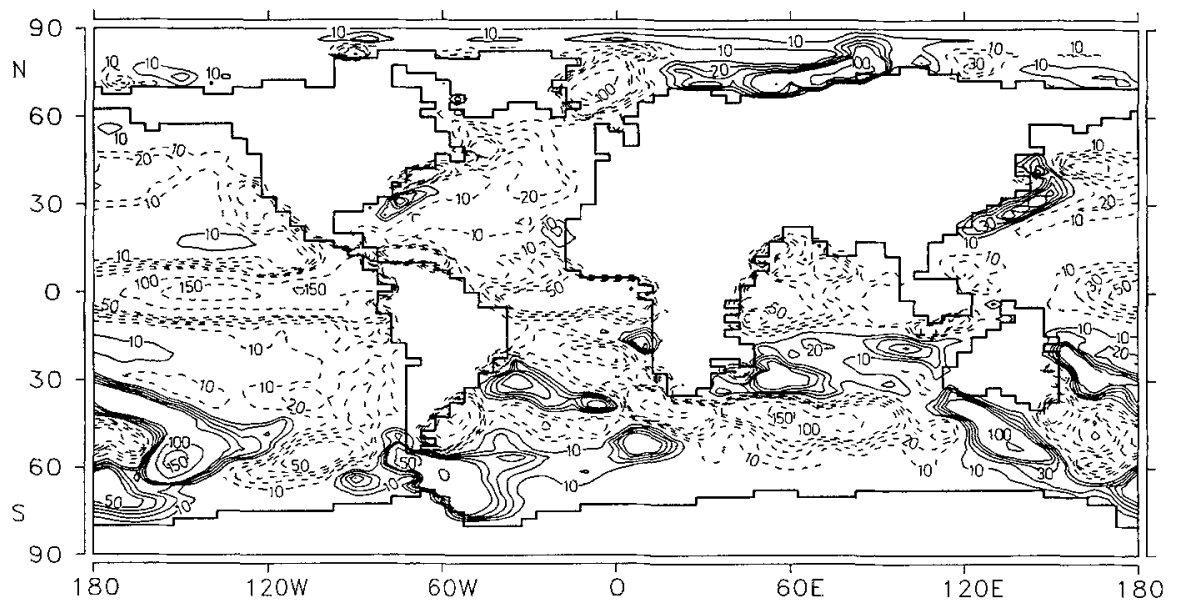

Fig. 7. Sea-air heat flux of the oceanic model in the uncoupled mode (Isoline intervals as in Fig. 6) 

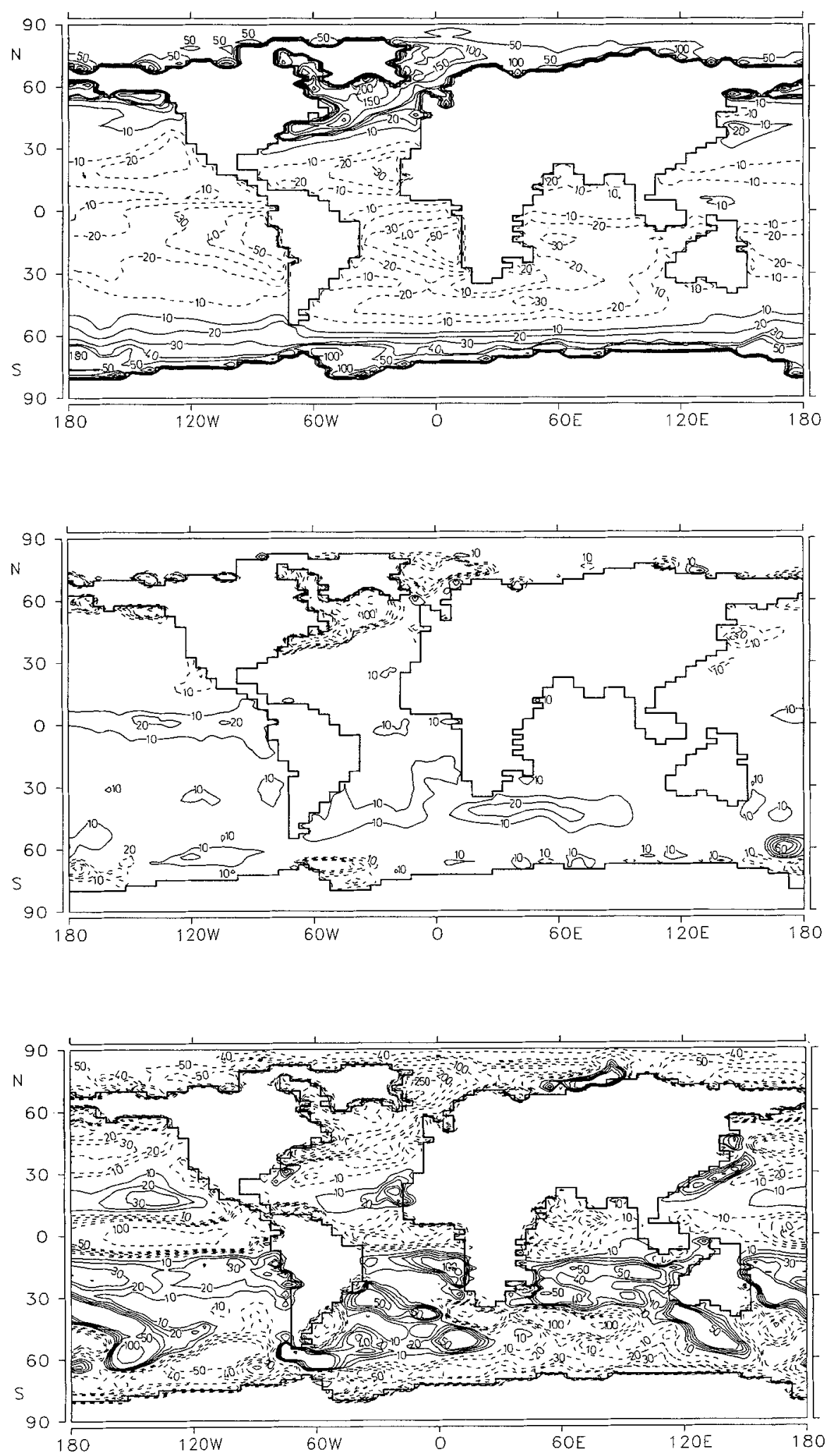

Fig. 8. Sea-air heat flux computed for the boundary values corresponding to the equilibrium states of the uncoupled models. (Isoline intervals as in Fig. 6)

Fig. 9. Flux correction for the atmosphere. (Isoline intervals as in Fig. 6)
Fig. 10. Flux correction for the ocean (Isoline intervals as in Fig. 6) 


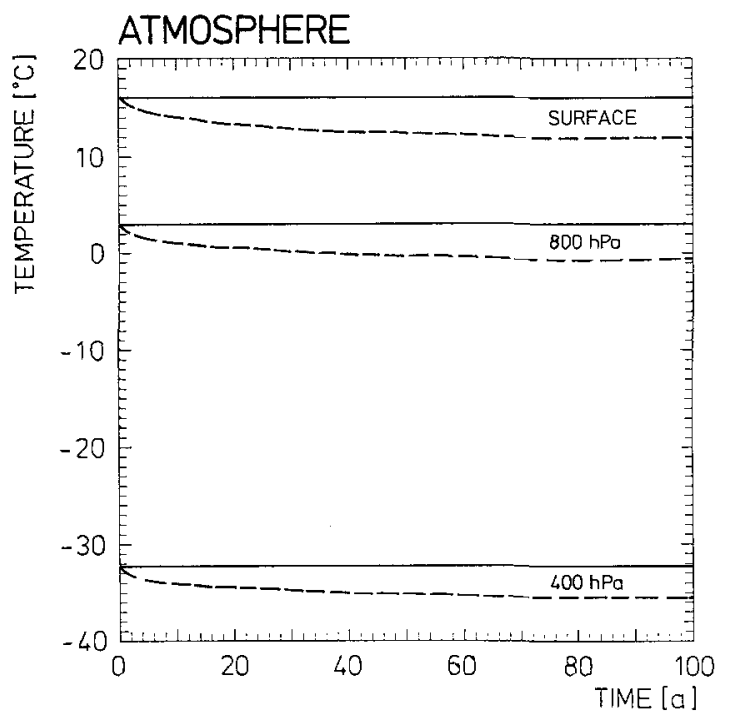

Fig. 11. Temporal evolution of the global mean temperatures of the atmosphere in the coupled model, without flux correction (dashed line) and with flux correction (solid line)

take longer to reach an equilibrium than the surface layers.

The drift in the ocean is also removed after introduction of the flux correction. The rms deviation of the temperature from the initial value (Fig. 15) is decreased by one to two orders of magnitude. The residual drift may be largely attributed to a residual drift of the uncoupled oceanic model. The rms deviation of the temperature of the uncoupled oceanic model is also shown in Fig. 15 (dash dotted lines). In this experiment the ocean was forced by a fixed prescribed heat flux computed from the initial oceanic boundary values. A forcing of this form without feedback tends to make a model unstable. However, the model errors do not grow abnormally within the first 1100 years of integration, although the rms deviation is larger than the rms deviation of the coupled model with flux correction (which includes a stabilizing radiation feedback).

The horizontal patterns of the temperature change at $75 \mathrm{~m}$ and $1000 \mathrm{~m}$ depth after 100 years integration are shown in Figs. 16 and 17, respectively. Without flux correction, the temperature change is rather large over most of the oceanic regions. With flux correction, the drift is nearly completely removed. At the $75 \mathrm{~m}$ level, only 24 and 72 gridpoints out of a total of 3382 exhibit temperature changes greater than $1 K$ and $0.5 K$, respectively. The corresponding numbers at the $1000 \mathrm{~m}$ level are 16 and 38. Most of the residual drift can be attributed to the drift of the uncou-
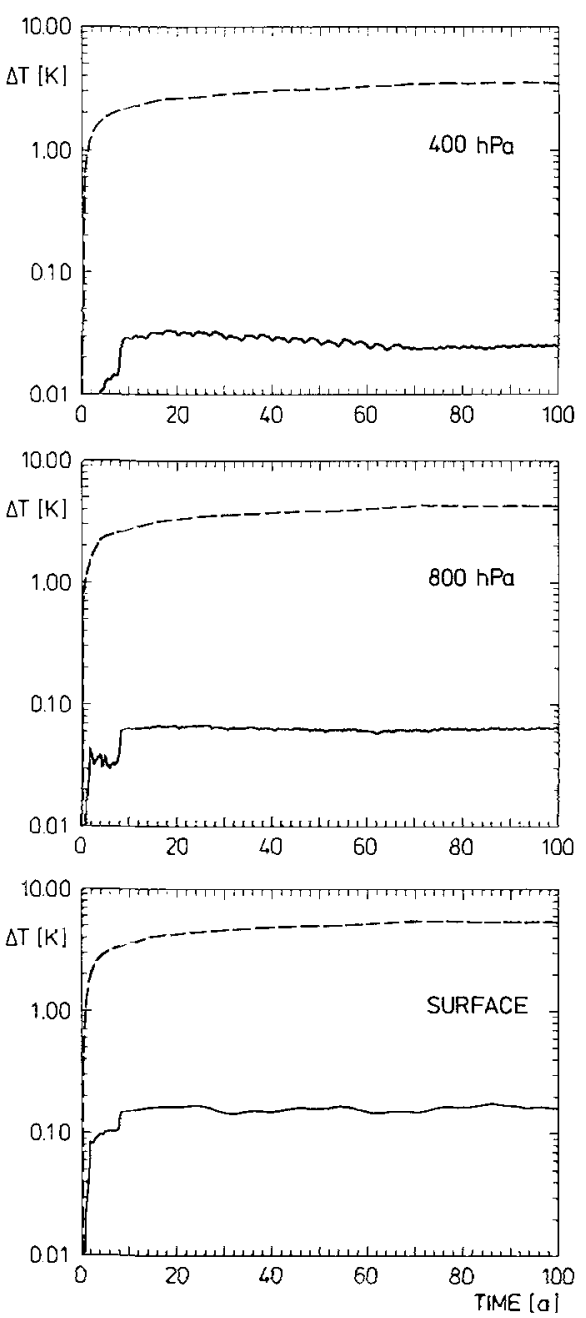

Fig. 12. Temporal evolution of the rms deviation of the atmospheric temperature from the initial values, without flux correction (dashed lines) and with flux correction (solid lines)

pled oceanic model, as indicated by Figs. 16c and $17 \mathrm{c}$.

\section{A climate response experiment}

To test the impact of the flux correction method in a climate response application, a " $\mathrm{CO}_{2}$ experiment" was carried out in which the absorbtion coefficients for long wave radiation were slightly increased. The change in the global mean temperature of the ocean due to the increased absorption coefficients is plotted in Fig. 18. The difference in the response for the experiments with and without flux correction is evident, especially for the lower levels. As the response has not yet achieved an equilibrium after 100 years (cf. Fig. 14), the equilib- 

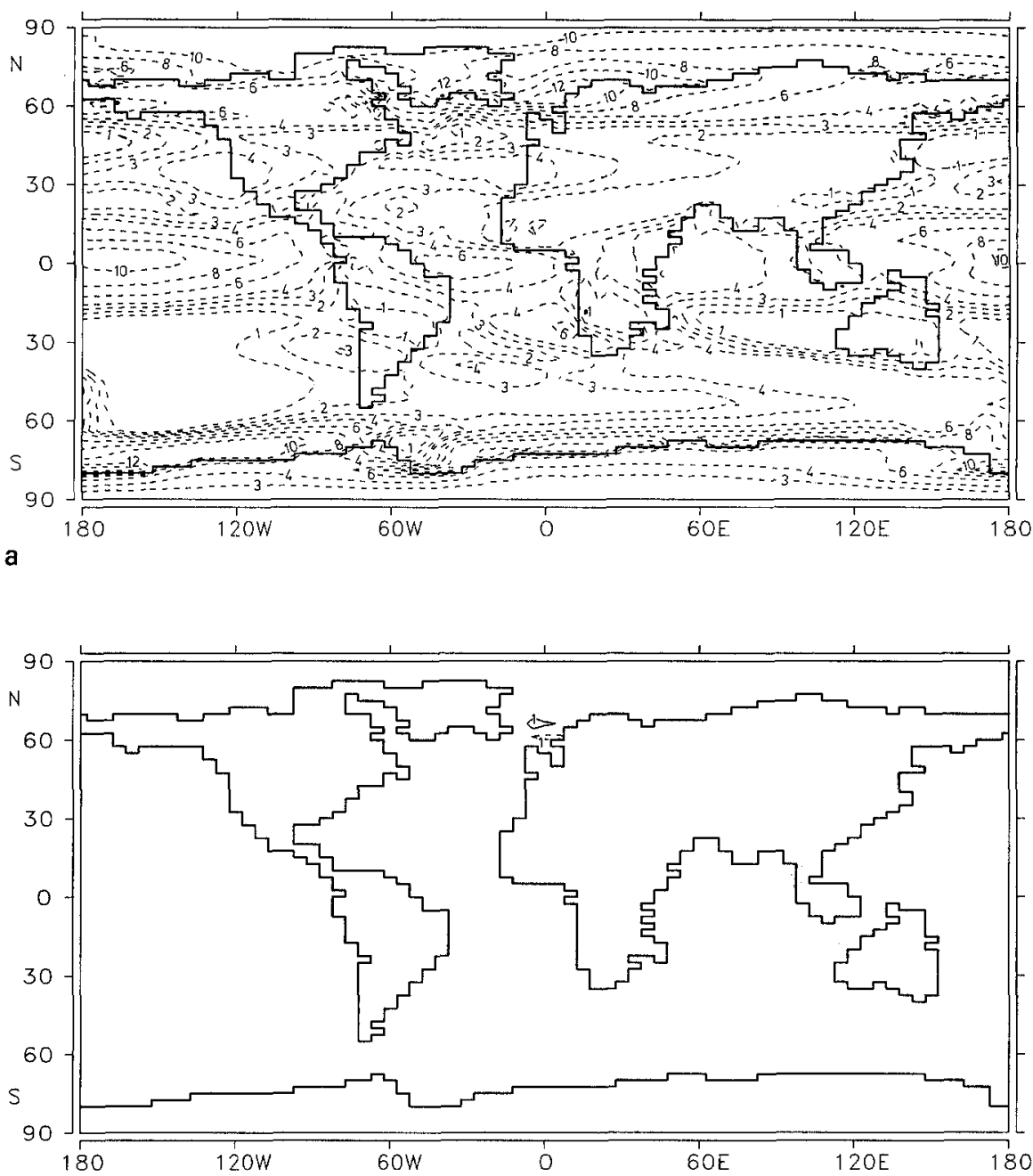

b
Fig. 13 a, b. The temperature change in 100 years at $800 \mathrm{hPa}$, without flux correction a and with flux correction $b$. Isoline intervals are $1 K$ below $4 K, 2 K$ above $4 K$. The zero line is not plotted, negative isolines are dashed

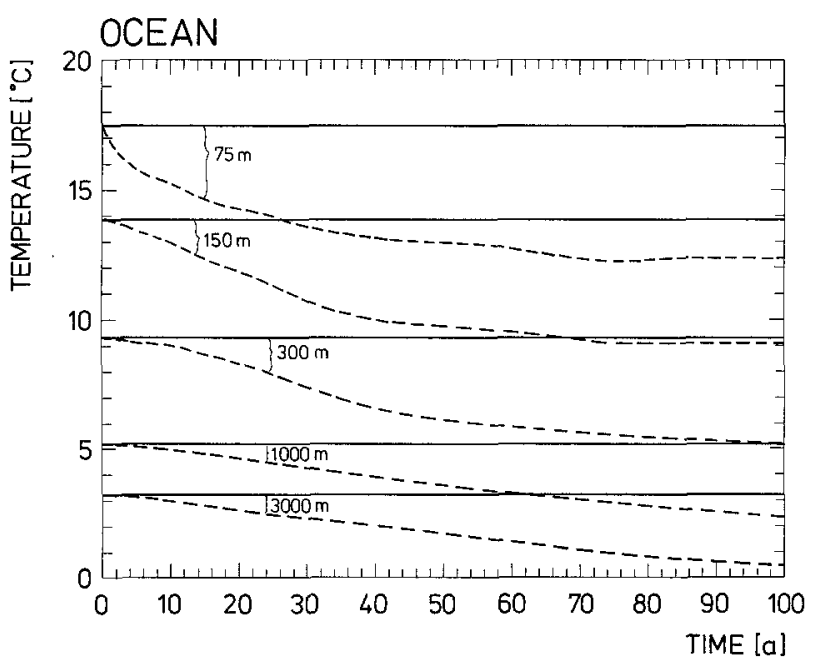

Fig. 14. Temporal evolution of the global mean temperatures of the ocean in the coupled model, without flux correction (dashed line) and with flux correction (solid line) brium differences between the experiments with and without flux correction will be even larger.

The local differences in the response of the ocean upper layer $(75 \mathrm{~m})$ temperature for the experiments with and without flux correction are plotted in Fig. 19. The differences in the response are evident, although the present coupled model does not include strongly non-linear effects such as variable sea-ice. Without flux correction the response patterns are generally noisier and can be regarded as significant only for the largest spatial scales.

\section{Conclusions}

The flux correction method presented here has been shown to successfully remove the drift in coupled atmosphere-ocean models. The method has been demonstrated both for a simple nonli- 

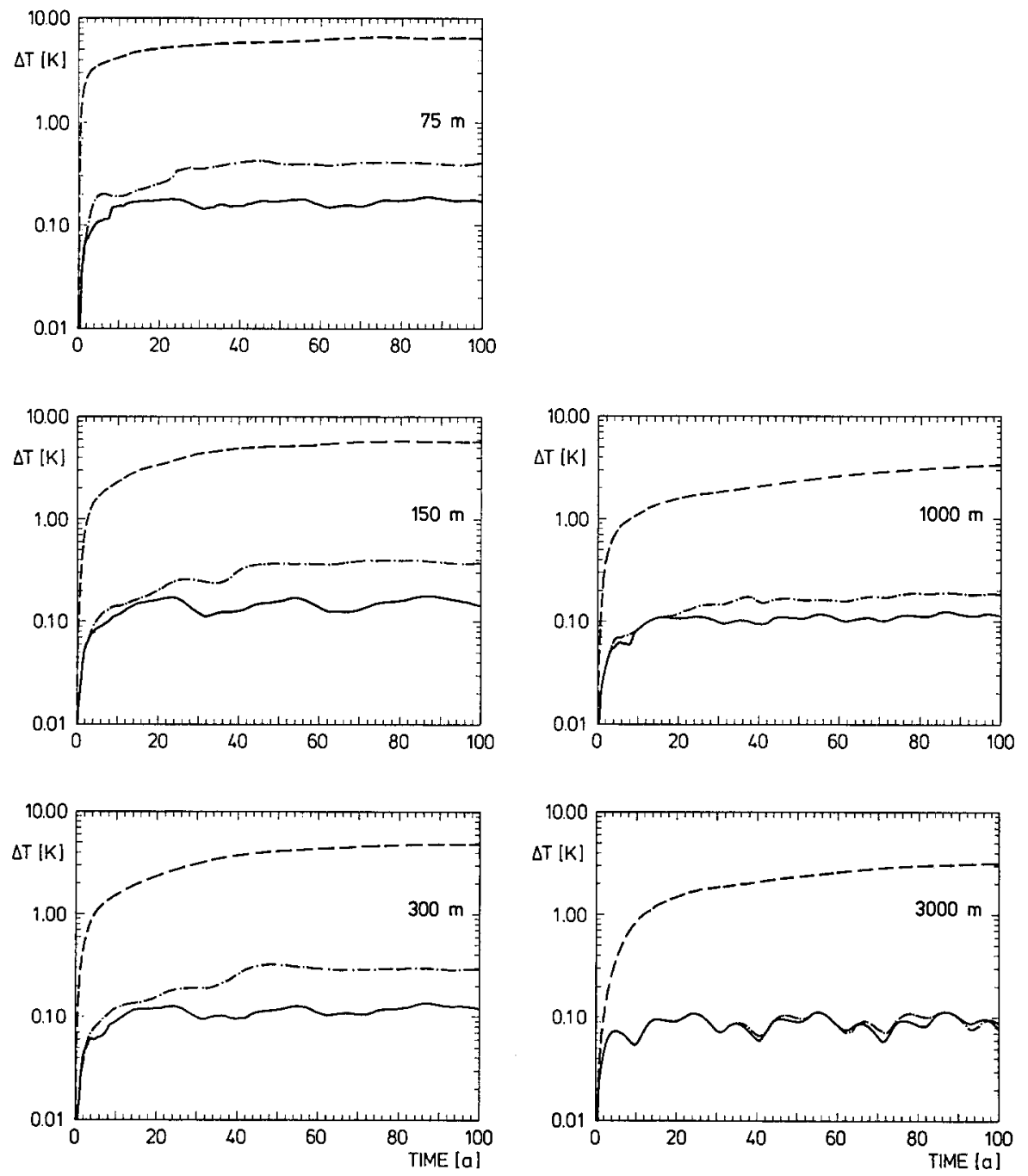

Fig. 15. Temporal evolution of the rms deviation of the oceanic temperature from the initial values without flux correction (dashed lines), with flux correction (solid lines) and for the uncoupled ocean (dash dotted lines)

near atmosphere-ocean model with two degrees of freedom and an OGCM coupled to a simple two level diagnostic model of the atmosphere.

The application of the method is basically straightforward and requires only diagnostic computations of the fluxes coupling the two sub-systems, using boundary values taken from observations or experiments run in the uncoupled mode.

The flux correction removes only the drift arising from the mean flux inconsistencies of the separate sub-systems. Stochastic flux variations associated with the internal variability of the subsystems, which can also give rise to model drift, are not removed. Although stochastic terms were not included in the present simulations through the application of a diagnostic atmospheric model, the terms generally represent real physical processes rather than model deficiencies and should therefore be retained. Corresponding low frequency variations are also observed in the real climate system and must be similarly taken into account when interpreting the climate response to prescribed external variations.

Finally, we note that the flux correction method is useful not only as a technique for maintaining the coupled model at the "working point" for which the model sub-systems were designed, but also as a diagnostic tool. The flux correction fields show the structure of the mutual inconsistencies of the separate sub-systems, indicating where modifications in the separate sub-system are most needed. 

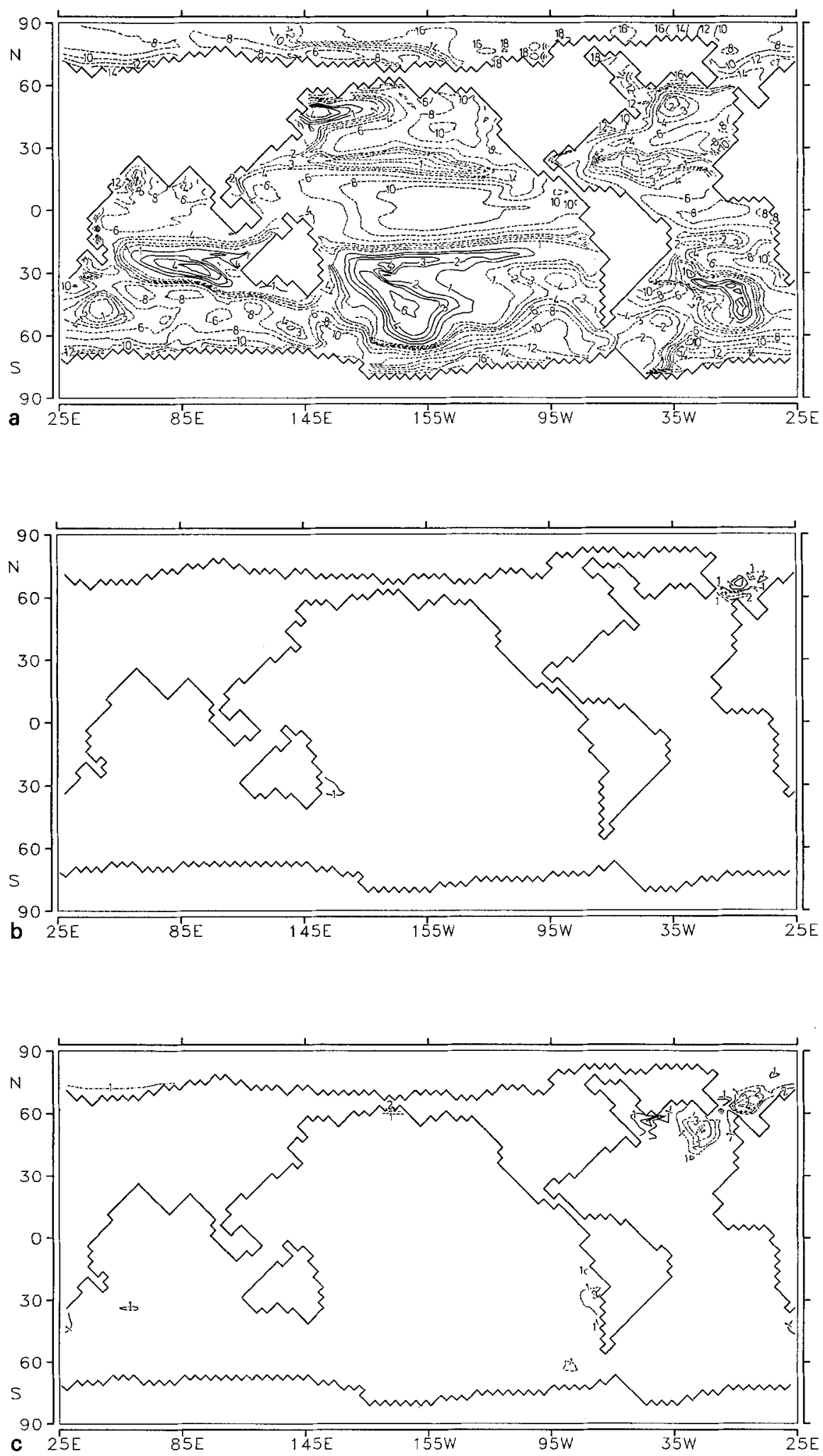

Fig. 16 a-c. Temperature drift over 100 years at $75 \mathrm{~m}$ depth, without flux correction a, with flux correction $b$, and for the uncoupled ocean c. (Isoline intervals as in Fig. 13) 

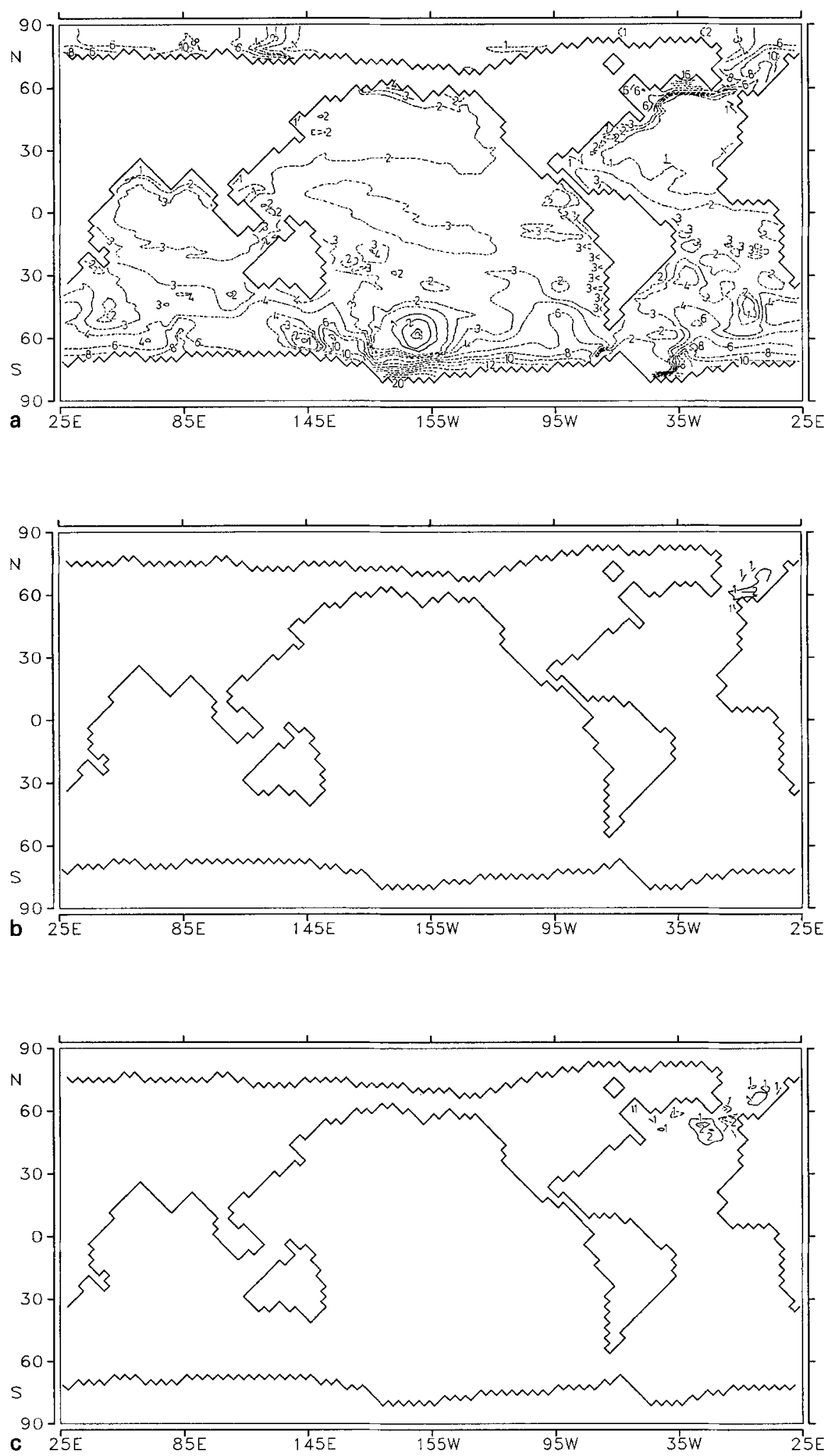

Fig. 17. Same as Fig. 16, but for $1000 \mathrm{~m}$ depth. (Isoline intervals $1 K$ ) 


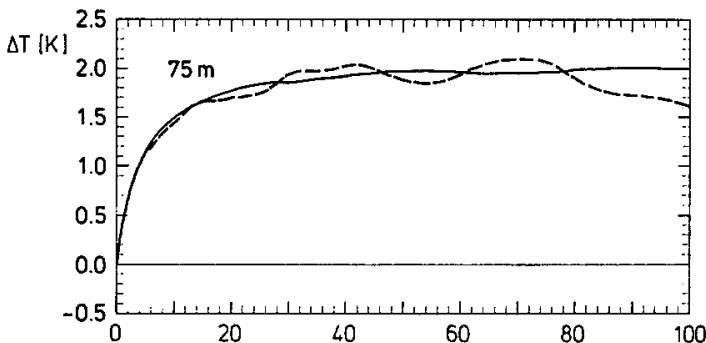

Fig. 18. Temporal evolution of the oceanic temperature response to the increased long wave absorption, without flux correction (dashed lines) and with flux correction (solid lines)
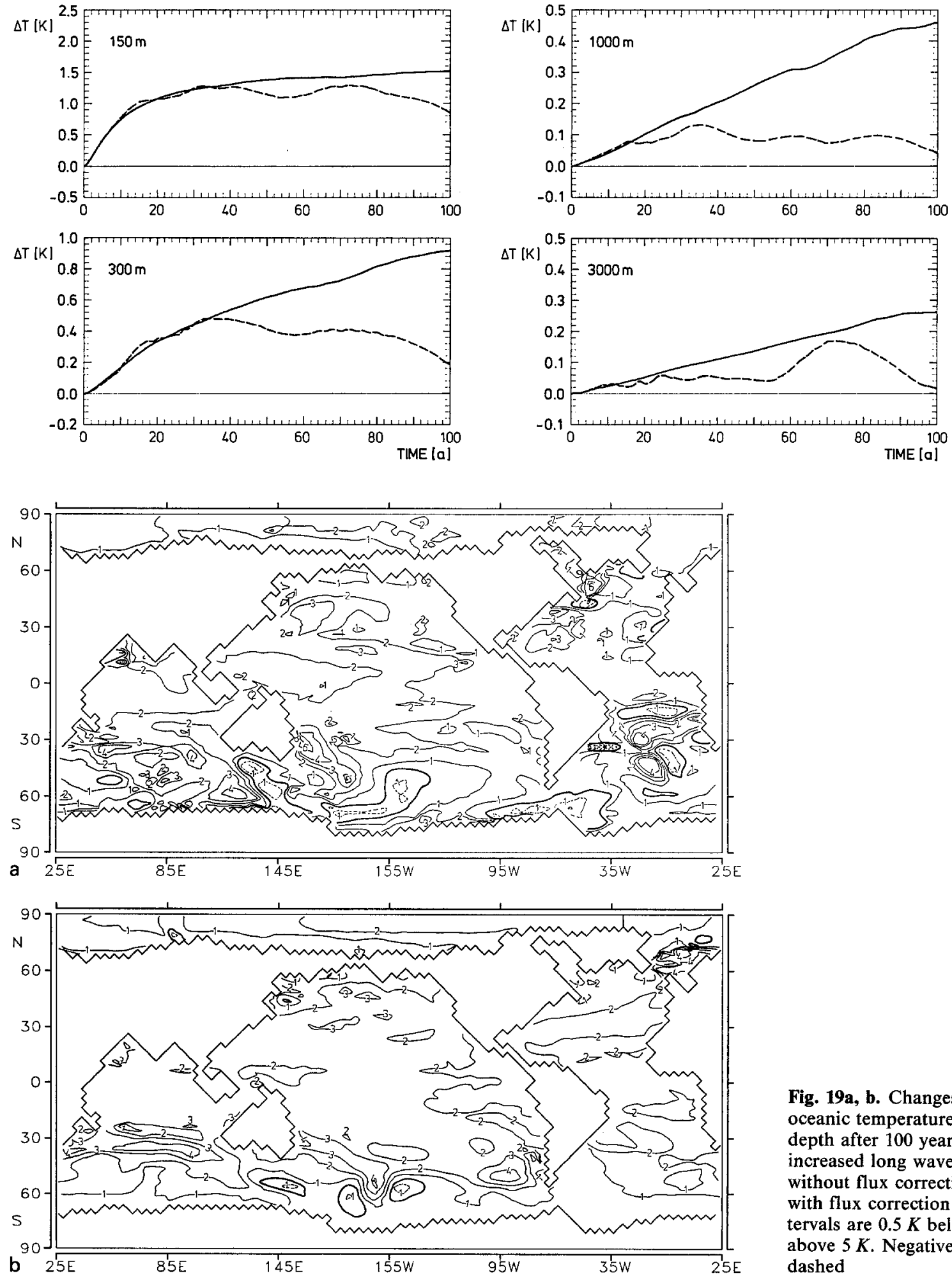

Fig. 19a, b. Changes of the oceanic temperatures at $75 \mathrm{~m}$ depth after 100 years due to the increased long wave absorption, without flux correction a and with flux correction b. Isoline intervals are $0.5 \mathrm{~K}$ below and $1 \mathrm{~K}$ above $5 K$. Negative isolines are dashed 


\section{References}

Biercamp J (1986) Interaktive Kopplung von ozeanischen Deckschichtmodellen an atmosphärische Zirkulationsmodelle. Annalen der Meteorologie (neue Folge) 23:74-75

Coakley JA (1979) A study of climate sensitivity using a simple energy balance model. J Atm Sci 36:260-269

Gates WL, Han Y-J, Schlesinger ME (1985) The global climate simulated by a coupled atmosphere-ocean general circulation model: Preliminary results. Coupled ocean-atmosphere models, Elsevier Oceanography Series 40:131151

Hansen J, Lacis A, Rind D, Russel G, Stone P, Fung I (1984) Climate sensitivity: Analysis of feedback mechanisms. Climate processes and climate sensibility. Geophysical Monograph 29:Maurice Ewing, Vol 5, Amer Geophys Union, Washington, 130--163

Hasselmann K (1976) Stochastic climate models. Part I: Theory. Tellus $28: 473-485$

Hasselmann K (1982) An ocean model for climate variability studies. Prog Oceanog 11:69-92

Hellerman S (1967) An updated estimate of the wind stress on the world ocean. Mon Wea Rev 95:606-626

Levitus S, Oort AH (1977) Global analysis of oceanographic data. Bull Am Met Soc 58:1270-1284

Maier-Reimer E, Hasselmann K, Olbers D, Willebrand J (1983) An ocean circulation model for climate studies. Techn Report, Max-Planck-Institut für Meteorologie, Hamburg, 34 pp

Maier-Reimer E (1985) A large scale ocean circulation model. Techn Report, Max-Planck-Institut für Meteorologie, Hamburg

Maier-Reimer E, Hasselmann K (1987) Transport and storage of $\mathrm{CO}_{2}$ in the ocean - an inorganic ocean-circulation carbon cycle model. Climate Dynamics 2:63-90

Manabe S, Bryan K, Spelman MJ (1979) A global ocean-atmosphere climate model with seasonal variation for future studies of climate sensitivity. Dyn Atmos Oceans 3:393426
Manabe S, Stouffer RJ (1980) Sensitivity of a global climate model to an increase of $\mathrm{CO}_{2}$ concentration in the atmosphere. J Geophys Res 85 C:5529-5554

Mitchell JFB, Lupton G (1984) A $4 \times \mathrm{CO}_{2}$ experiment with prescribed changes in sea temperatures. Progress in Biometeorology $3: 353-374$

Mitchell JFB, Wilson CA, Cunnington WM (1986) On $\mathrm{CO}_{2}$ climate sensitivity and model dependence of results. Submitted for publication. (Available as DCTN 28, Dynamical Climatology Branch, Meteorological Office, Bracknell Berkshire RG12 2SZ, England)

Oort AH (1983) Global atmospheric circulation statistics, 1958-1973. NOAA Professional Paper 14:180 pp

Sarmiento JL, Bryan K (1982) An ocean transport model for the North Atlantic. J Geophys Res 87 C:394-408

Sausen R (1986) Gekoppelte Ozean-Atmosphären-Modelle ohne Drift der prognostischen Variablen. Annalen der Meteorologie (neue Folge) 23:82-83

Sausen $R$ (1988) A radiative convective model including advection by prescribed winds. Meteorologisches Institut der Universität Hamburg. Large Scale Atmospheric Modelling Report

Sausen R, Barthel K, Hasselmann K (1987) A flux correction method for removing the climate drift of coupled atmosphere-ocean models. Max-Planck-Institut für Meteorologie, Hamburg, Report No. 1, 39 pp

Schlesinger ME, Gates WL, Han Y-J (1985) The role of the ocean in $\mathrm{CO}_{2}$-induced climate change: preliminary results from the OSU coupled atmosphere-ocean general circulation model. Oregon State University, Climatic Research Institute, Report No 60,35 pp

Washington WM, Semtner AJ, Meehl GA, Knight DJ, Mayer TA (1980) A general circulation experiment with a coupled atmosphere, ocean and sea ice model. J Phys Oceanogr 10:1887-1908

Received July 8, 1987/Accepted November 4, 1987 